\title{
Oil, power and social differentiation: a political ecology of hydrocarbon extraction in Ghana
}

\author{
Nathan Andrews ${ }^{1}$ \\ University of Northern British Columbia, Canada
}

\begin{abstract}
While there is scholarship focused on the nexus between resource extraction and development, further examination is needed of how the harms and benefits of extraction are differentiated among different stakeholders based on factors such as their access to power, authority over decision-making, social status, and gender. This article combines theoretical insights from assemblage thinking and political ecology to unpack the intertwined range of actors, networks, and structures of power that inform the differentiated benefits and harms of hydrocarbon extraction in Ghana. The study shows that power serves as a crucial ingredient in understanding relations among social groups, including purported beneficiaries of extractive activities, and other actors that constitute the networked hydrocarbon industry. The different levels (i.e. global, national, subnational, local) at which the socio-ecological 'goods' and 'bads' of hydrocarbon extraction become manifest are relational. The article contributes to ongoing scholarly and policy discussions around extractivism by showing how a multi-scalar analysis reveals a more complex picture of the distributional politics, power asymmetries, and injustices that underpin resource extraction.
\end{abstract}

Keywords: Political ecology, power, social differentiation, scale, environmental justice, hydrocarbon, Ghana

\section{Résumé}

Des recherches sont nécessaires pour déterminer comment les préjudices et les avantages de l'extraction des ressources sont différenciés entre les parties prenantes en fonction de facteurs tels que leur accès au pouvoir, leur autorité sur la prise de décision, leur statut social et leur sexe. Cet article combine des connaissances théoriques de la pensée d'assemblage et de la « political ecology » pour dévoiler la gamme entrelacée d'acteurs, de réseaux et de structures de pouvoir qui informent les avantages et les inconvénients de l'extraction d'hydrocarbures au Ghana. L'étude montre que le pouvoir est un ingrédient crucial pour comprendre les relations entre les groupes sociaux, y compris les soi-disant bénéficiaires des activités extractives, et d'autres acteurs qui sont en réseau dans l'industrie des hydrocarbures. Il existe des relations entre les différents niveaux auxquels les « biens » et les « mauvaises » de l'extraction d'hydrocarbures deviennent manifestes (c'est-à-dire mondial, national, sous-national, local). L'article contribue aux discussions scientifiques et politiques sur l'extractivisme. L'analyse multi-scalaire révèle une image plus complexe de la politique de distribution, des asymétries de pouvoir et des injustices qui sous-tendent l'extraction des ressources.

Mots-clés: écologie politique, pouvoir, différenciation sociale, échelle, justice environnementale, hydrocarbure, Ghana

\section{Resumen}

\footnotetext{
${ }^{1}$ Dr. Nathan Andrews, Associate Professor, Department of Global and International Studies, University of Northern British Columbia, Prince George, BC V2N 4Z9, Canada. Email: nathan.andrews "at" unbc.ca. The field research that informs this paper was undertaken during a Banting Postdoctoral Fellowship at Queen's University, Canada. I am very grateful for the financial and institutional support during this period. An initial draft of this article benefited from well-appreciated feedback from my colleague, Adeniyi Asiyanbi. I also appreciate the various stakeholders who made time to share their perspectives and experiences with me during fieldwork as well as the editors and anonymous reviewers of the JPE for facilitating this publication.
} 


\section{Introduction}

Hydrocarbons remain central to many economies despite the growing interest in alternative and more sustainable sources of energy. Since the discovery of commercial quantities of oil and gas in 2007, Ghana has attracted the attention of many international institutions and investors who see potential for this bourgeoning sector to contribute to broad-based socio-economic development. A decade since oil production commenced in 2010, it remains to be seen whether this expectation has been realized, including the conditions that mediate such expected outcomes.

In trying to explore this conundrum, several scholars focusing on Ghana have turned to the 'resource curse' as a conceptual framing that explains why certain resource-rich countries benefit from natural resource abundance and why others do not (see Cavnar, 2008; Gyampo, 2010; Okpanachi \& Andrews, 2012; ObengOdoom, 2014; Phillips et al., 2016; Graham et al., 2019). This article expands on this scholarship by pointing to an assemblage of actors, networks, and structures of power that inform the outcomes of resource extraction. The fact that Ghana's hydrocarbon industry is relatively new provides opportunities to explore this complexity and to inform the theoretical and policy implications of the politics of (re)distribution and benefit-sharing that occurs in the local hydrocarbon sector, and in other extractive industries elsewhere.

The core question is as follows: How are benefits and harms of hydrocarbon extraction distributed and differentiated among various stakeholders and what are the multi-scalar configurations and power structures that inform such outcomes? Here, I seek to explore the ways in which people's access to power and their control over decision-making, as well as their social status and gender, mediate the ramifications of extraction for their lives. This understanding facilitates a movement away from binary descriptions that characterize extractive activities as either good or bad, by showing how the positive and negative outcomes of these activities are often co-constitutive, relational, and socially engineered by actors and networks operating at different scales. The article therefore seeks to contribute to recent scholarship that highlights the complexity of Ghana's hydrocarbon industry by exposing the nested forms of agency, multi-scalar structures and relationships that underpin it (see Ayelazuno, 2014; Ablo \& Overå, 2015; Phillips et al., 2016; Siakwah, 2017, 2018; Ablo, 2018).

The next section briefly examines some theoretical insights from assemblage thinking and political ecology with a focus on the three main themes (i.e. power, environmental justice and scale) that are core to the ensuing discussion. This is followed by an overview of the methods used for primary data collection. The subsequent section presents data from fieldwork to explore the politics of scale, social differentiation and environmental (in)justice in the hydrocarbon industry. A brief concluding section follows this detailed empirical analysis.

\section{Assembling the political ecologies of power, scale and (in)justice}

This article employs assemblage thinking to bring together and frame political ecology themes such as power, scale and (in)justice. Emerging from actor network theory, assemblage thinking implies "the relational coming together and spatial ordering of disparate entities through which actions occur" (Hewitson \& Sullivan, 2021, p. 8). In other words, everything is connected, and this perspective helps to illuminate the nested forms of actor-coalitions, power structures and systemic injustices that underpin the manifestations of political and 
socio-ecological processes. As Latour (2005, p. 204) notes, "no place dominates enough to be global and no place is self-contained enough to be local." Yet, Appel (2012) has shown that offshore oil is enclaved, and the act of disentanglement creates a problematic spatial and phenomenological distance between the sector and its real-world consequences. The utility of assemblage thinking is that it dismantles this framing by re-entangling these supposedly disparate sectors and their respective spheres of impact. In fact, applications of the assemblage perspective in existing research on the extractive industry point to a set of globalized configurations that shape and, to some extent, determine the outcomes and manifestations of resource exploitation (see Smith, 2010; Gilberthorpe \& Rajak 2017, Siakwah, 2017, 2018; Andrews \& Siakwah, 2021).

\section{Understanding power, (in)justice and scale}

Along the lines of assemblage thinking, political ecology showcases how the distinction between the natural and the social is artificial considering the complex intersectionality of political, economic, sociocultural and ecological processes (see Walker, 1998; Watts, 2000; Robbins, 2004; Nygren \& Rikoon, 2008; Blaikie, 2012). The aspects of political ecology that are important to this contribution include power, scale, and (in)justice - all of which contribute to a better understanding of the complex set of processes, actions, and structures that manifest in a hydrocarbon economy. Central to political ecology theorizing is the notion of power or 'power politics' (see Svarstad et al., 2018). With an understanding of politics as "the practices and processes through which power, in its multiple forms, is wielded and negotiated" (Paulson et al., 2003, p. 209), one of the core objectives of political ecology is therefore to understand the complexities around how power becomes constructed and distributed, how power circulates in the social field, how power connects social and natural fields, and how power determines the age-old dichotomy of who gets what, when and how (see Lasswell, 1950; Bryant, 1998; Gleeson \& Low 2002). With particular reference to the topical focus of this article, it has been posited that "resource extraction has a long history and extensive geographical reach [that is] ... also tied to who has the power to do what, where, how cost effectively, and for whose benefit" (White, 2013, p. 52; see also Le Billon, 2001; Watts, 2004; Zalik, 2009). This point underscores how ecological conditions and environmental change resulting from resource extraction represent a by-product of political processes and structures.

Another political ecology theme that unites the concepts of social justice, vulnerability and marginalization is environmental justice, as it exposes "the lived experience of the reality of injustice on the ground, in the air, in one's food, at the workplace or school, and on the playground" (Schlosberg, 2013, p. 51). Environmental justice theorizing entails global (and local) environmental struggles that are focused on distributive and procedural justice, which foreground issues relating to access to resources and people's inclusion or involvement in decision making that could have implications for such access (for an overview, see Agyeman, 2005; Walker \& Bulkeley, 2006; Schlosberg, 2007; Sze \& London, 2008; Holifield et al., 2009; Walker, 2009, 2012; Blaikie, 2012; Agyeman \& McEntee, 2014). Environmental injustice in this context implies that people do not have access to resources that could improve their lives and they are also excluded from decision-making processes that may reverse the trend of distributive injustice (Schroeder et al., 2008). Here too, power remains an important ingredient in deciphering who has access to what, when and how. With particular reference to the hydrocarbon industry, the distributive justice element nicely unites political ecology and environmental justice (Svastad and Benjaminsen 2020).

In understanding the complex processes at play in political ecology, scholars have also drawn our attention to the importance of scale (see Swyngedouw \& Heynen, 2003; Neumann, 2009; Charles, 2012; Haarstad, 2014a). While recognizing the ambiguity surrounding the meaning of scale as either size or level (see Marston et al., 2005), I am more interested in the multiple levels at which power asymmetries and the "scalar practices of social actors" (Moore, 2008, p. 212) are manifested in the hydrocarbon economy. Size, of course, matters. However, concerns of scalar practices and power relations are quintessential to what Neumann (2009, p. 399) refers to as the "political ecology of scale." As governance is a multi-level issue, so is power and the politics that inform such processes by which decisions are made and benefits distributed. This complex understanding of scale sheds light on the global-local continuum or across-scale linkages that inform a meaningful evaluation of hydrocarbon outcomes. It also helps us to appreciate how the power-laden nature of 
the socio-ecological relations is constantly shifting "between groups of actors and scales" (Swyngedouw \& Heynen, 2003, p. 914; see also Haarstad, 2014b). Latour (2005) points to how the local is global and the global is local; this perspective facilitates an appreciation of scale as nested within a complex set of structures and processes that tend to defy straightforward differentiation.

\section{Theorizing Ghana's hydrocarbon political ecology}

Both political ecology and assemblage thinking as employed in this article point to the intersectionality of power, (in)justice and scale. This theoretical framing is made relevant in the case of Ghana when we explore the complex interactions occurring in extractive spaces where socially differentiated forms of power and benefits collide with forms of injustice and marginalization. Despite the essence of social differentiation in our understanding of environmental justice, an intersectionality of power, (in)justice and scale is of key importance, as depicted in Figure 1 below - which reflects the interactive influences of these different elements on each other. In sum, the discussion so far has reflected on all the key points that are part of these three intersecting elements. For instance, the fact that someone's livelihood is marginalized by not having access to the ocean for small-scale fishing due to offshore oil extraction is informed by the actions of a globalized assemblage of actors who also tend to have decision-making power over who gets to participate in the hydrocarbon economy. This point is vital to a more complete appreciation of how benefits and harms are socially differentiated and nested within other structures and systems.

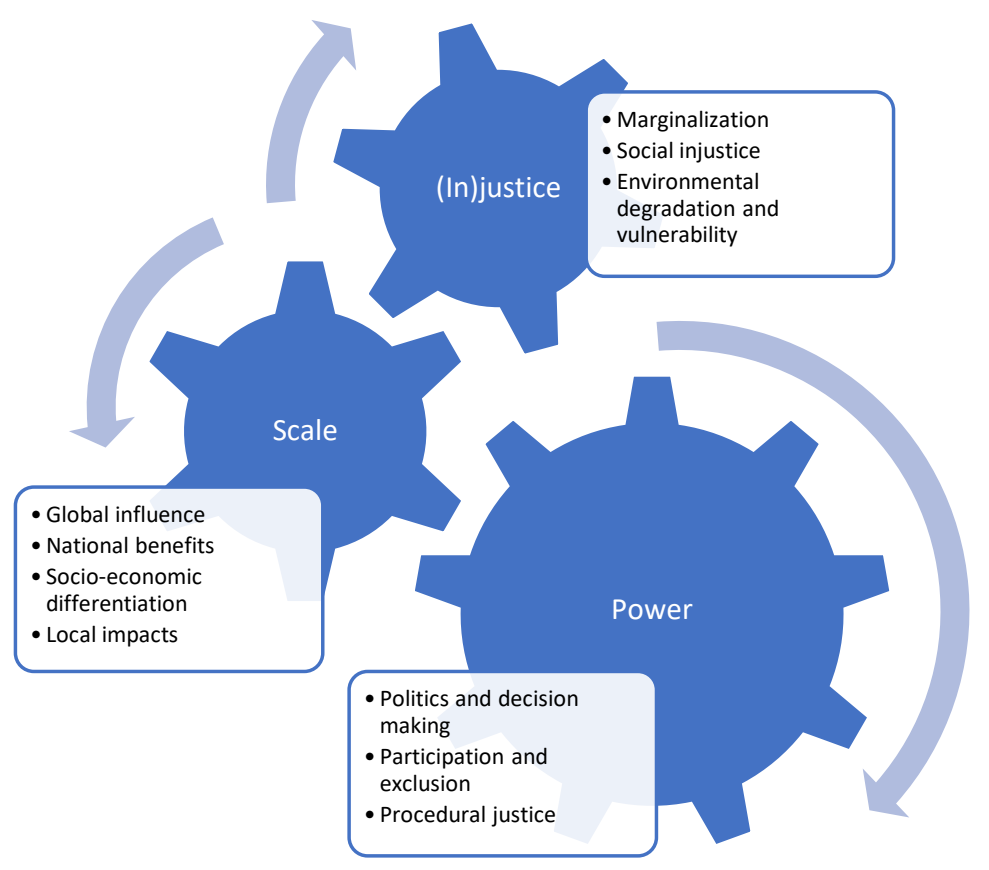

Figure 1: Some interacting elements of a hydrocarbon political ecology. Source: author.

As Swyngedouw and Heynen (2003, pp. 912-913), argue,

...socioecological processes give rise to scalar forms of organisation-such as states, local governments, interstate arrangements and the like-and to a nested set of related and interacting socioecological spatial scales. In addition, these territorial scalar arrangements intersect—often in contradictory and conflicting ways... 
This means that while actors operating at various scales in Ghana's hydrocarbon assemblage have differentiated access to power and socio-environmental justice, the outcomes of such differentiation can also be best understood as co-constitutive. Such an intersection reveals contradictions whereby actors' access to redistributive power cannot be judged solely on the basis of the scale at which they are explicitly seen to be operating, especially considering the interwoven nature of the networks they belong to. It also sheds light on why an offshore transnational oil company (TOC) will prefer to be seen as a 'good neighbor' or corporate citizen through proactive social interventions even though the oil enclave is perceived to be disentangled from the impacts the industry has on neighbouring communities (see Appel, 2012).

To sum up, scale unveils the complexity of the environment within which hydrocarbon extraction occurs. As already alluded to, a discussion of scale reveals the relational nature of the different levels (i.e. global, national, sub-national, local) at which the socio-ecological impacts of hydrocarbon extraction become manifest. In the empirical discussions to follow, scale also facilitates a more nuanced appreciation of how the impacts and benefits of industrial activities in Ghana are distributed and differentiated along the lines of social status, gender and access to power or control over resource distribution (Ablo, 2018; Nyantakyi-Frimpong \& Bezner Kerr, 2017; Andrews, 2013; Adusah-Karikari, 2015; Ackah-Baidoo, 2013). Such social differentiation is important in helping us capture the varieties of socio-environmental 'goods' and 'bads', including the multiple actors and processes involved in negotiating and distributing these outcomes (Andrews \& Siakwah, 2021).

\section{Methodological background}

As an exploratory study, this research employed a case study design which has been described as an empirical approach that provides in-depth analysis and description of a phenomenon (see Yin, 2017; Creswell \& Poth, 2017). A case study design is a useful approach for two reasons. First, Ghana's hydrocarbon industry is still in its infancy - considering that oil production commenced in 2010. Thus, a case study is useful in helping to explore not only the structures within which hydrocarbon extraction occurs but also the agents and various networks of actors that underscore a growing economy. Despite its infancy, the hydrocarbon industry is booming. Information on the Petroleum Commission's website as of May 2019 indicated that there are 17 active Petroleum Agreements covering different offshore concessions as shown in Figure 1. The majority of these concessions are located in the Western basin, which justifies the focus of the study on Ghana's Western Region. Second, the majority of the recently published research on the industry has used a similar design to explore its different socio-economic and environmental ramifications at different scales (e.g. Ackah-Baidoo, 2013; Andrews, 2013; Ayelazuno, 2014; Ablo \& Overå, 2015; Adusah-Karikari, 2015; Siakwah, 2018; Ablo, 2018).

\section{Data collection}

Primary data is drawn from fieldwork conducted between May and August 2016 in Ghana, in addition to secondary data such as published articles and news reports. With an attempt to identify the broader political ecology of hydrocarbon extraction, the fieldwork engaged with a variety of stakeholders drawn from the Western Region and beyond. This included six coastal communities such as Axim, Busua, Dixcove, Cape Three Points, Sekondi-Takoradi and Ngyiresia in addition to Accra - the capital city. In particular, the six coastal communities were selected because they are fishing-reliant communities that are among those residing near offshore oil production activities (see Figures 2 and 3). As a result of their proximity, they are also among the list of communities expected to either benefit from or to experience the harms of such activities. A total of 84 participants were involved in the study and data was collected using community interviews, focus group discussions and interviews with elites. By being present in the selected communities for the duration of the study, participant observation was also used to understand the themes of power, scale, social differentiation, and environmental justice. The fusion of these different data collection techniques helped to ensure reliability of the information retrieved. 


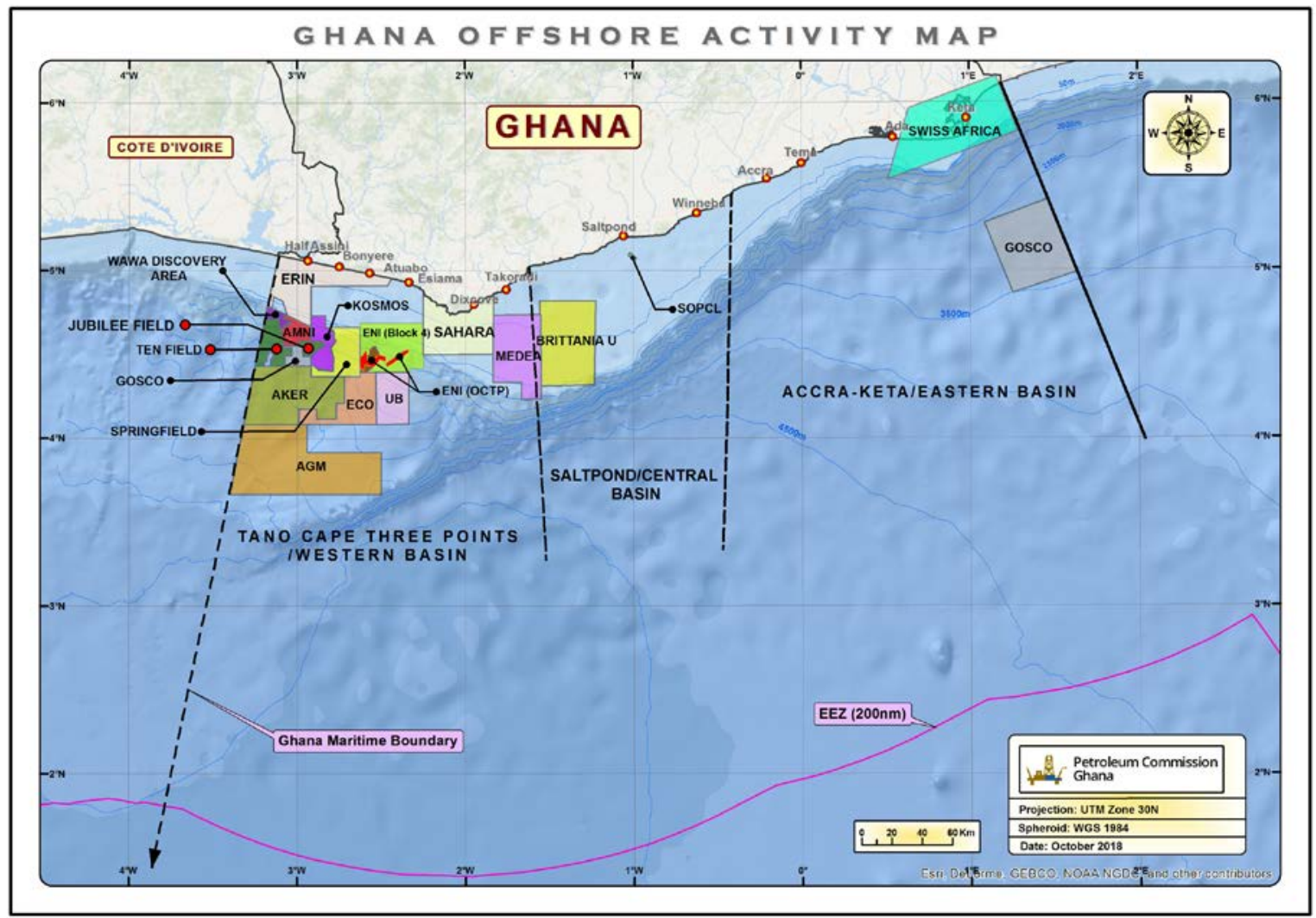

Figure 2: Ghana's Offshore Hydrocarbon Fields. Source: Petroleum Commission, Ghana: https://www.petrocom.gov.gh/maps/ (accessed 10 May 2019).

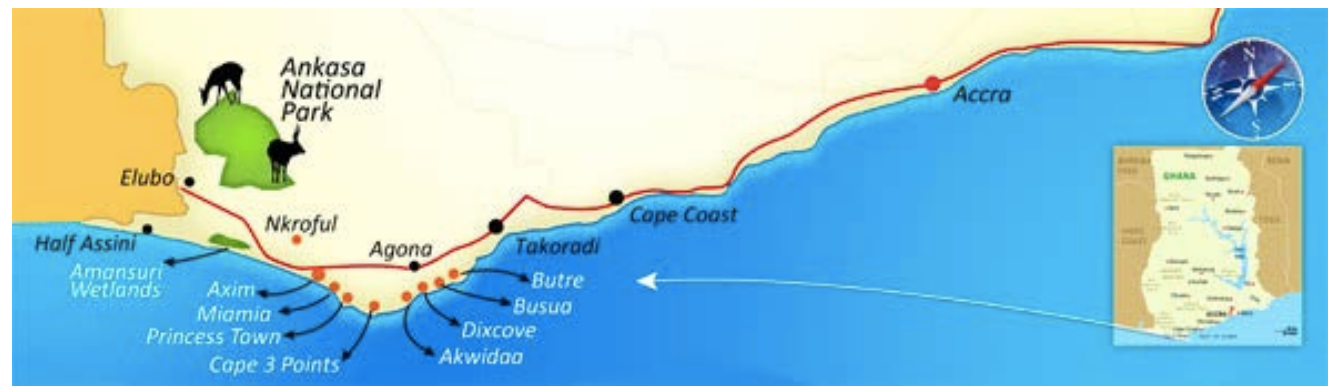

Figure 3: Towns on Ghana's West Coast. Source: http://ghanawestcoast.com (accessed 9 May 2019)

The sample comprised elite interviews $(n=40)$ involving corporate executives, government officials, representatives of international organizations, NGO representatives, academics and members of the mass media; community interviews ( $\mathrm{n}=17)$ involving traditional authority and fisherfolk in selected communities; and six focus groups ( $\mathrm{n}=27$ ) involving fisherfolk, youth and members of community-based organizations. Following a purposive sampling technique, the total number of participants involved and the duration of 
interviews and focus groups (averaging between 30 and 45 minutes) was determined by theoretical saturation - that is, the point at which further responses did not yield new and important information. Questions asked entailed the actual and perceived benefits/impacts of hydrocarbon extraction on peoples' livelihoods, including the differentiated dimensions of such impacts and benefits at the local and national levels. Involving a diverse group of stakeholders facilitated a complex understanding of the importance of politics, scale and social differentiation in the hydrocarbon economy. Interviews and focus group discussions were recorded with the consent of most participants (refused: $n=4$ ). The recorded data were transcribed verbatim and lightly edited for further analysis alongside handwritten fieldnotes. Participants had the option of remaining anonymous but several of them provided consent for their names and professional designations to be used. Nevertheless, majority of the fieldwork insights used in this article are anonymized.

\section{Data analysis and interpretation}

The analysis of the data involved a four-step process that included familiarization, theme identification, data reduction via coding, and interpretation. As part of the first step, familiarization and theme identification was done by carefully reading and sorting out transcripts to reveal key themes and issues that cut across the various documents. After the major themes became obvious upon repeated reading of transcripts, a codebook was developed (see Saldaña, 2015) to capture these themes and their meanings. The third step (i.e. data reduction) was systematic coding using the MAXQDA software, which offers effective coding of data via memos, comments and annotations (Saillard, 2011; Nie, 2017). The thematic coding process across the entire dataset resulted in a total of 980 coded segments (i.e. relevant narratives and quotes across all responses) from 58 transcripts and seven document groups. These coded segments emerged from 48 themes and sub-themes that covered the bigger project that informs this article. The article relies on a few of these themes - particularly those that shed light on the connections between socio-political and ecological understandings in Ghana's hydrocarbon industry.

The fourth stage of analysis (data interpretation) occurred by making sense of the various thematic segments both in light of existing literature on the topic and across-code responses. Coded segments were reread to ensure internal consistency, although consistency in exploratory or interpretive research is not entirely feasible (Gioia et al., 2013). At least, this iterative data interpretation process helped to reveal points of disjuncture and intersection between the data and extant scholarship, as well as among the responses of the various stakeholders who participated. Nonetheless, the limit of this study lies in the fact that it is an in-depth qualitative inquiry of an individual country (i.e. Ghana) and a single aspect of the economy (i.e. hydrocarbon industry). This means that while the analysis below may reflect patterns in other resource-rich countries on the African continent and elsewhere, widespread generalizability was not a core objective of this work.

\section{Findings and discussion}

\section{Power politics and scales of hydrocarbon benefit}

As discussed in the theoretical section, one of the core objectives of political ecology is to understand the complexities around how power becomes constructed and distributed, how power circulates in the social field, how power connects the social and natural fields, and how power determines who gets what, when and how (Lasswell, 1950; Smith, 1974; Bryant, 1998; Gleeson \& Low, 2002; Svarstad et al., 2018). This is important in the hydrocarbon industry because existing evidence has revealed that resource extraction as a whole is "tied to who has the power to do what, where, how cost effectively, and for whose benefit" (White, 2013, p. 52). Power in this context implies the ability to wield control over the distribution of resources. It is also worthy of note that power can be indirect and discursive if "actors such as corporations, government agencies or NGOs, produce discourses and manage to get other groups to adopt and contribute to the reproduction of their discourses" (Svarstad et al., 2018, p. 356). The point is that in an extractive economy, actors have different access to such distributive authority, mostly informed by who they are, where they are from, who they know and what socio-political networks they belong to. Table 1 below provides an 
(inexhaustive) snapshot of the various actors that make up the hydrocarbon assemblage, their power differentials as well as what they stand to gain and/or lose from the existence of the industry. Rather than merely depicting a top-down hierarchy of power relations, the power differentials and expected (or real) benefit and harms underscore how power circulates in various socio-political and ecological spaces and how actors have access to it or not, depending on the scale at which they are operating.

The power differential of actors at the global scale tends to be high. They include powerful foreign state actors such as Norway (a grant giver and an exemplar country to follow), the U.K. (through the work of its Department for International Development) and China (as an investor ${ }^{2}$ ) as well as non-state actors (or 'donor' institutions) such as the World Bank, the United Nations Development Programme (UNDP), and the German Agency for International Cooperation (GIZ) among others (Oppong \& Andrews, 2020). These actors usually have a high incentive to ensure that the hydrocarbon industry does well. The World Bank, in particular, has undertaken a US\$55 million oil and gas capacity building project to boost the efforts of government in building the institutions needed to regulate and manage the industry. This funding has greatly benefited the Ministry of Energy and Petroleum, resulting in the establishment of the Petroleum Commission to replace the Ghana National Petroleum Corporation (GNPC) as the regulator of the upstream hydrocarbon industry. The Environmental Protection Agency and other institutions in Ghana also benefited from this project, which has the objective of building the capacity and expertise of locals to fully participate in and benefit from oil and gas development (interview with World Bank petroleum expert, Accra).

Despite this expected benefit, such financial support gives global forces the power to influence the sector by propagating certain ideas and so-called norms of 'best practice'. As one World Bank financial analyst noted, "I mean there is no silver bullet ... But I think what is more important is that the Ghanaian government does understand that it cannot extract and extract the value of its natural resources without private sector partnership" (interview, Accra). This officer admitted that though the World Bank does not usually dictate a particular neoliberal (i.e. FDI-oriented) policy, its loans and grants come with certain conditions that are meant to help state ministries make the 'tough decisions' that will advance the economic interests of their countries. But this begs the question of whether capacity-building projects are meant to strengthen the state and its human resource, or rather push for continuous neoliberal private sector investment in the industry.

Another important set of global actors are the TOCs themselves who have a power and incentives to stabilize the hydrocarbon economy in order to expand their assets and increase their shareholders' returns, even amidst fluctuating global commodity prices. These TOCs include Tullow Oil, Kosmos Energy, ENI, Hess Corporation, Anardarko Petroleum, and PetroSA among others. In particular, Tullow, Kosmos, ENI and Hess are among the leading companies in Ghana with contracts that began as early as July 2004 (e.g. Kosmos). This gives them some power over other corporate actors in the industry - considering that the official announcement of an oil find in commercial quantity (the Jubilee field) was made in 2007. As such, these corporate actors have been able to spearhead other finds such as the Tweneboa Enyenra Ntomme (TEN) oil field which began production in 2016. Tullow Oil currently owns $47 \%$ of the TEN field whereas Kosmos and Anadarko have $17 \%$ each; Petro SA maintains a minimal 3.8\%. ${ }^{3}$ Although the GNPC holds a $15 \%$ stake in the field, the majority of the equity is owned by global forces who possess significant access to and control over the industry. For the Jubilee field, the equity is divided as follows among Tullow (35.48\%), Kosmos (24.08\%), Anadarko (24.08\%), GNPC (13.64\%), and Petro SA (2.73\%). ${ }^{4}$ Here too, the majority of the equity (over $85 \%$ ) remains in the hands of TOCs.

In discussions with government and corporate executives about different developments in the industry, I was directed to refer to what Tullow is doing or to speak directly with them (interview with Kosmos executive, Accra). This is because, for both the Jubilee and TEN fields, this company maintains the position as 'operator'

\footnotetext{
${ }^{2}$ For China's 'oil diplomacy' in Ghana, see https://journals.openedition.org/poldev/2408 (accessed May 29, 2019).

${ }^{3}$ See https://www.tullowoil.com/our-operations/africa/ghana/ten-field/ (accessed June 20, 2021).

${ }^{4}$ See https://www.tullowoil.com/our-operations/africa/ghana/jubilee-field/ (accessed June 20, 2021).
} 
and leader whereas others are named as 'partners.' Tullow has the authority over shutdowns and other activities ${ }^{5}$ that have direct implications for socio-economic, political and biophysical environments. According to company executives, Tullow's role has meant it leads the Jubilee partners to undertake social interventions costing about US\$25 million in areas such as scholarships for local students, water management, and alternative livelihoods (interview with Tullow CSR executive, Accra). All these projects, though yet to reflect strongly in the lives of purported beneficiaries (see Osei-Kojo \& Andrews, 2020), have nonetheless further solidified the power and dominance of Tullow and other corporate actors (see also Andrews, 2021). As further evidence of Tullow's power and gains, the company in May 2019 revealed plans to invest an additional \$250 million in light of Ghana's 'bright hydrocarbon future' and the company's quest to continue playing a leading role in the industry. ${ }^{6}$ The scale at which TOCs are operating and the discursive power they possess in order to establish dominance explains why the benefits of hydrocarbon extraction accruing to them are significant.

At the state level, there are different perspectives on the centrality of power in politics. As it relates to Ghana's extractive industry, the concepts of political settlements and competitive clientelism in particular have become popularized because they explain the "the centrality of inter-elite power relations and clientelist politics in shaping development processes and their outcomes" (Abdulai, 2014, p. 8). The belief is that "Ghana's ruling elites and parties have built an environment conducive to achieving economic growth, poverty reduction and improved levels of human development" (Oduro et al., 2014, p. 23). This means that there is, in fact, an elite commitment to ensuring some degree of socio-economic and political stability because it serves them and their coalitions well to do so. Recent evidence exists to support this perspective (Ayanoore, 2018). As one journalist noted, "the political class influences who get hired, who gets licences to work in the industry. They want to see [whether] if you make money you will support their party because it their time to eat. So yes, the politics are influencing how the oil sector is doing" (interview with journalist, Accra). Another journalist remarked that "the politicians are not talking about oil because they want the good of the general public. They are talking about oil because of what will go into their pocket" (interview with journalist, Accra).

These two observations above provide some background to the 'turf war' that has been ongoing at the GNPC between the Chief Executive Officer (CEO) and the Board Chairman, who disagreed in 2019 over the process for the recruitment of a procurement officer. ${ }^{7}$ The power to appoint leaders of state institutions rests with the President. Yet, once appointed, these officers are expected to operate at arms-length from incumbent governments. But, obviously, this is exactly the issue in this case where the CEO argues that the Chairman appointed by the current NPP government is interfering in a recruitment process which is primarily his function to perform. While this evidence points to the prominence of power politics and a potential patron-client relationship that speaks to other things the CEO has been accused of, ${ }^{8}$ political settlements and competitive clientelism perspectives are not necessarily nuanced. This is because they tend to suggest a zero-sum game that imagines power as predetermined and fixed, thereby concealing the role and agency of the variety of actors that make up the entire hydrocarbon assemblage. Power is indeed relational and exerted at different scales of this assemblage; so are benefits and harms manifested at these different levels, as can be seen in Table 1 .

\footnotetext{
${ }^{5}$ For instance, see https://www.offshoreenergytoday.com/tullow-plans-three-jubilee-fpso-shutdowns-in-2018/ (accessed May 29, 2019).

${ }^{6}$ See https://www.myjoyonline.com/business/2019/may-25th/tullow-oil-plans-250m-investment-in-ghana-operations.php (accessed May 29, 2019).

${ }^{7}$ See https://citibusinessnews.com/2019/02/ies-urges-nana-addo-to-resolve-gnpc-ceo-board-chairman-impasse/ (accessed May 29, 2019).

${ }^{8}$ For recent conflict of interest accusation, see https://www.graphic.com.gh/news/politics/ghana-news-kk-sarpongresponds-to-imani.html (accessed May 29, 2019). See also, https://citinewsroom.com/2018/08/gnpc-ceo-authorised-7-5mtransaction-with-his-former-company/
} 


\begin{tabular}{|c|c|c|}
\hline Actors & $\begin{array}{l}\text { Power } \\
\text { differential }\end{array}$ & Benefits and harms (expected or actual) \\
\hline Global (state \& non-state) & High & $\begin{array}{l}\text {-Power of influence over hydrocarbon legislation, institutions } \\
\text { and governance } \\
\text {-Increased investment in different aspects of the industry (e.g. } \\
\text { loans and grants to fund related projects) }\end{array}$ \\
\hline Global (TOCs) & High & $\begin{array}{l}\text {-Expanded global assets } \\
\text {-Increased revenue base and shareholder returns } \\
\text {-Fluctuations in global commodity prices }\end{array}$ \\
\hline National (state) & High & $\begin{array}{l}\text {-Legislative improvement resulting in better management (e.g. } \\
\text { petroleum law and revenue management act) } \\
\text {-Improved efficiency leading to increased revenue (e.g. } \\
\text { establishment of PIAC) } \\
\text {-Maintaining the GNPC as a competitor in the industry }\end{array}$ \\
\hline $\begin{array}{l}\text { Sub-national (metropolitan } \\
\text { assemblies) }\end{array}$ & Medium to high & $\begin{array}{l}\text {-Increased population in the Western region and Sekondi- } \\
\text { Takoradi Metropolitan Assembly resulting in higher revenues for } \\
\text { developmental purposes } \\
\text {-Improved road and other infrastructure to accommodate oil } \\
\text { boom } \\
\text {-High cost of living, including oil-led gentrification } \\
\text {-Overcrowding, resulting in high expenses }\end{array}$ \\
\hline $\begin{array}{l}\text { Sub-national (NGOs \& policy } \\
\text { experts) }\end{array}$ & Medium to high & $\begin{array}{l}\text {-Boom in the efforts of civil society organizations and think- } \\
\text { tanks (e.g. ACEP, CDD, IMANI Africa, CSPOG etc.) } \\
\text {-Opportunities to expand advocacy into coastal communities } \\
\text {-More funding and networks to advance effective stakeholder } \\
\text { engagement in the hydrocarbon industry (e.g. Western Region } \\
\text { Coastal Foundation) } \\
\text {-Resist or campaign against socio-environmental injustice (e.g. } \\
\text { Friends of the Nation) } \\
\text {-Policy experts moving into 'high-power' positions (e.g. Dr. } \\
\text { Mohammed Amin Adam formerly of ACEP as current Deputy } \\
\text { Minister of Energy in charge of petroleum) }\end{array}$ \\
\hline $\begin{array}{l}\text { Local entrepreneurs (e.g. } \\
\text { fisherfolk and business } \\
\text { people) }\end{array}$ & Medium & $\begin{array}{l}\text {-Access to growing market for business activities (e.g. trading, } \\
\text { services, supplies, hospitality, transportation, etc.) } \\
\text {-Establishment of local content provisions to ensure goods and } \\
\text { services are procured in-country and the establishment of } \\
\text { Enterprise Development Centre to advance such objectives } \\
\text {-Potential access to alternative livelihood options for fisherfolk } \\
\text { due to dwindling stock of fish and exclusive zones set up due to } \\
\text { extraction }\end{array}$ \\
\hline $\begin{array}{l}\text { Local coastal community } \\
\text { leaders (e.g. chiefs) and } \\
\text { 'ordinary' members (e.g. men, } \\
\text { women and youth) }\end{array}$ & $\begin{array}{l}\text { Low to medium to } \\
\text { high }\end{array}$ & $\begin{array}{l}\text {-Chiefs and other leaders gain benefits as custodians or } \\
\text { spokespersons of local communities } \\
\text {-Access to opportunities for employment and other livelihood } \\
\text { activities } \\
\text {-Bare harshest brunt of local socio-economic and environmental } \\
\text { impacts (different from 'local' in Takoradi, for instance) }\end{array}$ \\
\hline
\end{tabular}

Table 1: Actors, relations of power and hydrocarbon benefits/harms. 
The sub-national scale is interesting, as actors range from metropolitan assemblies to civil society organizations (CSOs) who have different incentives and power differentials ranging from medium to high. The Sekondi-Takoradi Metropolitan Assembly (STMA), for instance, speaks of a boost in the activities of members of its Chamber of Commerce who are 'making it big' by taking advantage of the opportunities created by the booming hydrocarbon industry and the population influx. According to the Public Relations Officer of the STMA, "the oil find for Sekondi-Takoradi has been quite good in terms of revenue for the [metropolitan] assembly" (interview, Takoradi). The investment in the region has also resulted in many beneficial infrastructural projects (e.g. roads, port expansion, 'world class' hotels) but has also resulted in skyrocketing cost of living in Sekondi-Takoradi and other coastal communities. For instance, the average person can no longer afford the accommodation they had about five years ago due to increased rents - with some homeowners charging in U.S. dollars and others converting their properties into hotels and guest houses for expatriates and other oil workers (interview with Coordinating Director for STMA, Takoradi). I consider this to be a gradual process of gentrification that could eventually take away key residential areas from the hands of locals, thereby marginalizing their access to tracts of land that have historically supported their livelihoods. The case of Sekondi-Takoradi is especially interesting when we think of gentrification theory being formerly proposed as a model to explain urban shifts and status-driven residential movements in developed countries (see Eduful \& Hooper, 2015).

There has also been a boom in the efforts of CSOs, including the Africa Centre for Energy Policy (ACEP), Civil Society Platform on Oil and Gas (CSPOG), Publish What You Pay-Ghana Centre for Democratic Development (CDD-Ghana), and IMANI among a plethora of others. Regional-based organizations such as the Western Region Coastal Foundation (WRCF) and Friends of the Nation (FoN) have gained tremendous reputation and power in the industry. Founded in 2004, shortly before the announcement of the first oil find, IMANI has a dedicated Centre for the Study of Energy and Natural Resources and has therefore remained an important actor in the hydrocarbon industry. The organization, among other accolades, boasted of being ranked among the top 10 most influential policy think tanks in Africa for the previous five years. ${ }^{9}$ This means that the power of their advocacy has ramifications for the broader political ecology of extraction in terms of giving them the authority to speak and sanction certain policy ideas that could alter the livelihoods of people impacted by extractive activities. The evidence is a manifestation of the discursive power held by influential CSOs.

An organization like CDD-Ghana that is primarily concerned with 'democratic development' (e.g. party politics, democratic reform, political participation, civic engagement, governance, social accountability, corruption etc.) has nonetheless become quite notable in the hydrocarbon sphere - perhaps facilitated by a wellcited co-authored publication by both its former and present director (see Gyimah-Boadi \& Prempeh, 2012). Among CDD-Ghana's recently-appointed fellows are scholars and experts with interest in natural resource governance, energy policy, public corporate governance, private sector development, and public financial management - all of which connect with the hydrocarbon industry. While CDD-Ghana is still known for policy research into elections, governance and anti-corruption campaigns, it has gained further weight by dabbling in oil politics. I posit that these are benefits that are facilitated by the socio-political status of CDD-Ghana's core leadership who are seen to be respectable scholars and citizens by the organization's own networked affiliates domestically and abroad. In fact, the ability for CSOs to maintain medium to strong power also depends on the financial resources they have access to. Thus, while they are listed as 'sub-national' actors, these organizations are connected to a globalized assemblage of sponsors and donors, some of whom belong to powerful coalitions that influence the hydrocarbon industry. For instance, WRCF was established in 2014 with funds by the U.K.'s Department for International Development (DFID) to promote better multi-stakeholder engagement practices in the coastal communities impacted by extraction (interview with WRCF governance lead, 14 June 2016, Sekondi-Takoradi). This DFID funding augments WRCF's prominence, despite its relatively late entrance to the hydrocarbon realm.

Some policy experts and academics that are associated with CSOs, especially those who have produced knowledge about the industry, have benefitted from the hydrocarbon economy directly or indirectly. For

\footnotetext{
${ }^{9}$ See https://imaniafrica.org/our-reputation/ (accessed May 29, 2019).
} 
instance, the former director of ACEP (i.e. Dr. Mohammed Amin Adam) moved on to serve as Deputy Minister of Energy in charge of petroleum from 2017 to 2020, a Member of Parliament since January 2021, and again as Deputy Minister of Energy since June 2021. Other former ACEP officers have also moved on to positions with powerful institutions, for example, the Ghana Energy Commission and the USAID West Africa Energy Program. Also, a policy influencer such as Dr. Steve Manteaw who has been central to the formation of the CSPOG is now involved in high-level decision making as part of the Ghana Extractive Industries Transparency Initiative and the Public Interest Accountability Committee (PIAC). While these actors have been great advocates for accountability and transparency and have the requisite experience and qualifications to serve in such capacities, the point is that the current 'benefits' or status recognition they have gained as a result of the positions they hold leads to someone else's exclusion. Had they not been affiliated with their respective institutions and had they not been part of a group of renowned (elite) policy advocates, they would not have had access to such power in their current designations. This observation underscores the important role of social status and elite networking in determining who is included in decision making. Ultimately, the decline or non-existence of the industry will result in losses to them - hence the incentive to ensure its stability and vibrancy is maintained and persistently infused in popular policy and media discourses.

Though TOCs are characterized as maintaining strong power in the industry, they are also acutely aware of how power can shift. Local (so-called 'low-power') actors could organize against their activities in the Western Region. While it is yet to be seen, the organization of such a formidable social force could signal a shift in the power differential of local community members from low to medium or high, reminiscent of Latour's (2005) local-global continuum. This possibility means that power relations are, in fact, in constant flux. Political ecologists have been keen on identifying the role of human agency and how the structures of power can be contested in order to reclaim and assert alternative ways of social (re)production and management (see Robbins 2004; Nygren and Rikoon 2008; Blaikie 2012). In Ghana's hydrocarbon industry, however, one observer noted that "I'm afraid that agency is not coming out and this is not the first time that people have been dispossessed as a result of extraction... if you go to Obuasi, people's lives have been completely destroyed but they are not able to do anything" (interview with academic expert, Accra). This observation reflects the positionality of 'ordinary' community members as having 'low power' (see Table 1).

In the absence of this needed human (individual) agency, CSOs such as FoN are still serving as meaningful advocacy platforms. As noted by one officer, FoN provides the avenue "to directly engage the duty bearers such as the Environmental Protection Agency, the Ghana Maritime Authority, the Fisheries Commission, the Ghana Navy, the Ghana Air Force - all the various stakeholders who have a role to play in addressing community concerns" (interview with Natural Resources Governance Coordinator, Sekondi). Through its policy dialogues and advocacy campaigns, the organization is able to give prominence to issues such as marginalization, social justice, environmental degradation and vulnerability which were core to the concerns expressed by coastal community members during fieldwork. As a result of this work, FoN therefore benefits directly from the hydrocarbon economy due to its growing reputation as the go-to alternative voice or 'friend of the people.' Thus, it serves as a medium through which 'low-power' community members contend with powerful multi-scalar structures and actors.

Political ecology has an underpinning assumption that power relations between the state and other nonstate actors have implications not just for the socio-economic but also for the biophysical environment. Thus, although there appears to be a disconnect between politics and ecology in the discussion above, it underscores how environmental change resulting from oil extraction represents a by-product of political processes and power structures. Bob Jessop argued over a decade ago that "[i]t is not the state that acts; it is always specific sets of politicians and state officials located in specific parts and levels of the state system. It is they who activate the specific powers and state capacities in particular institutions and agencies" (Jessop, 2007, p. 38). Beyond the fetishization of state apparatuses in Jessop's work, we can see from the discussion here that a plethora of actors are part of the processes and structures that inform and condition extractive activities. This means that the multiple levels at which power structures and the "scalar practices of social actors" (Moore, 2008, p. 212) are manifested in the hydrocarbon industry of Ghana have broader implications for the political ecology of resource extraction. This understanding implies that power does not merely circulate out of nothing 
in the social field, but it has the ability to enact and control the multiple environments (i.e. socio-economic, political, biophysical) that different actors live and operate in.

\section{Social differentiation and environmental (in)justice}

Those who are enjoying [the benefits] from the oil production are enjoying and those of us who are suffering are really suffering. (Focus group discussion, Ngyiresia).

This observation by a female focus group participant underscores the social differentiation that illuminates the material manifestations of environmental (in)justice, as it reveals the sharp extremes of the benefits and harms of hydrocarbon extraction. It further explains why and how actors operating at multiple scales have access (or not) to certain socio-environmental 'goods' and 'bads' (see Svastad \& Benjaminsen 2020). In line with the argument made by Swyngedouw and Heynen (2003, p. 913), "power gradients within and between social groups, whether characterised along gender, class, ethnic or even ecological lines, reflect the scale capabilities of individuals and social groups" and such power underlie their potential contribution to the materiality of the environments in which they dwell. The importance of cross-scalar intersections and the contradictions embedded in them imply that environmental justice at the community level, albeit a local scale issue, is informed by actions and processes that go beyond this particular scale. Yet even by focusing on a single scale (e.g. 'local'), we can identify outcomes that are differentiated along the lines of social status and gender (Ablo, 2018; Nyantakyi-Frimpong \& Bezner Kerr, 2017; Adusah-Karikari, 2015; Ackah-Baidoo, 2013).

As can be seen above in Table 1, the local scale is specifically important to highlight here because not all locals are equal. For instance, someone residing in Takoradi who can be considered a local of the Western Region is different from a small-scale fisher in Cape Three Points or Dixcove who has limited or zero access to some of the economic opportunities that people in the major city have gained. This explains why scale and social differentiation is needed to understand who has access to or benefits from the gains of local content arrangements in the hydrocarbon industry. The argument is that, for instance, while the work of the Enterprise Development Centre in Takoradi is important to ensuring that hydrocarbon industry-related goods and services are procured locally among other entrepreneurial initiatives, these activities typically benefit a small group of suppliers and those with the technical expertise who can be employed in the industry (see Ovadia, 2016; Andrews \& Nwapi, 2018, Ablo, 2018).

Here too, the local homeowner who now has the opportunity to charge higher rent or convert their property into a guest house for commercial purposes can be differentiated from a local fisher who has lost full access to the ocean for small-scale fishing or is facing dwindling stock of fish catch, and yet is simultaneously faced with rising costs of living in an 'oil town.' This means that in towns like Axim and Dixcove, some locals are 'making it big' (as noted in an interview with municipal executives) while others are losing out on promised gains from resource extraction, which puts their well-being at risk. As one advocate indicated, "the question of livelihood is at stake. The question of the environment, the pollution of the environment, is at stake because flaring is going on. And the question of the micro-environment within the ocean is also a problem" (interview with WACAM officer, Tema). The livelihoods of coastal communities are at the centre of environmental justice. Apart from reduced access to the ocean due to the exclusive zones demarcated around the oil rigs, the fisherfolk highlighted that waste and seaweed inhibit a fruitful fishing expedition. Locals consider this to be one of the main environmental impacts of extraction, also documented in the existing literature (see AcquahBaidoo, 2013; Siakwah, 2018). The pollution referred to above was confirmed by interviewees - one of whom (a woman) mentioned that "the pollution of the air is making us sick, so we see no benefits" (interview, Cape Three Points).

Feminist researchers have already exposed how the human-environmental nexus is gendered (see Mollett \& Faria, 2013; Adusah-Karikari, 2015; Nyantakyi-Frimpong \& Bezner Kerr, 2017; Amongin, 2020). This means that the question of who is facing injustice and the sort of power they can access or not to mitigate such injustice is crucial. In particular, social status is important in understanding how different individuals in a 
community that is affected by extraction are impacted. In answering the question of whether the impact of extraction is differentiated along the lines of gender, a fishsellers' leader was emphatic: "Yes, it's us the women who struggle and take care of them. Reason being that you cannot eat while your husband and children are hungry" (interview, Ngyiresia). According to this woman, there is a vast gender difference because if the men come home with no catch, which is often blamed on the growth in offshore extraction, the women will have nothing to sell and will therefore end up with nothing to cater to the needs of their household.

Women play an instrumental role in households by making sure there is food on the table regardless of the hardships the family may be encountering (see Amongin 2020). For those who rely on smoking and selling fish as a livelihood activity, the dwindling stock of fish catch places them at a particular risk of not being able to provide for their families. For those involved in other forms of trade and occupation, the increased cost of living in many coastal communities still places them in a vulnerable position compared to men who may not be blamed if their households are not properly catered for. The fact is that "women who do the fish business are more than those with the provision [convenience] stores" (interview with fishseller, Dixcove). This observation implies that women's livelihoods are directly altered by the outcomes of fishing activities, which are also influenced by offshore extraction and the activities of multi-scalar actors in the industry.

To further reiterate the gendered nature of processes for distributing oil benefits, another woman noted that "we the women at the seashore buying the fish from the fishermen, we don't see the benefit of the oil. So maybe the [chief] fishermen do. As for them, they go for council meetings" (interview, Dixcove). Beyond the question of resource distribution, which is key to environmental justice, another point being raised here is procedural justice. Considering that recognition and participation are core to environmental justice (Schlosberg, 2013; Svarstad \& Benjaminsen, 2020), it is important to highlight the social differentiation that results in Chief Fishermen (and a few leading women) being invited to meetings where decisions that have direct impact on affected communities are made. As a fisherman in Dixcove pointed out during an interview, "they are aware that after [some] years, we will face serious problems. That explains why they keep training us on how you can set up your own business or how to manage your money." This was confirmed in a number of interviews with some leaders in the fishing industry who admitted that they are often called to important meetings held in expensive hotels (e.g. Busua Beach Resort), as part of efforts to understand their plights and help address them. At the end of these meetings, which are fully paid and catered for, these 'spokespersons' are offered some honorarium and other 'goodies.' The point here is that this form of inclusion in decision-making has direct implications on how access to resources is determined and differentiated (see Schlosberg, 2007; Sze \& London, 2008; Walker, 2009, 2012). Although the social status of those locals attending the meetings is elevated by virtue of being at the table with powerful actors such as TOCs, government functionaries and CSOs, the particular developmental outcomes of these meetings for respective communities are yet to materialize (interview with fishsellers' leader, Ngyiresia).

It is worth mentioning that chiefs and some opinion leaders in the Western Region insisted at the onset of oil production in 2010 that $10 \%$ of oil revenue be allotted to advance the development of the region. Per this request, a Western Region Development Fund should have been established under the Petroleum Revenue Management Bill (now Act) to adjudicate this revenue. But Parliament did not legislate this request into the Act despite the social status and political connections of the proponents. However, this request gained renewed traction upon the appointment of the new minister for the Western Region (Dr. Kwaku Afriyie) in 2017 who stated that the region deserves to receive $15 \%$ of total oil revenue ${ }^{10}$ but he was equally unsuccessful in convincing legislators to make this provision mandatory. There are, therefore, prevailing contestations around the benefits that should accrue to the region to counter any negative hydrocarbon impacts. Environmental justice is concerned with the basic needs of individuals and how communities can function effectively (Schlosberg, 2013). Thus, the distributive injustice that results from socio-ecological decision-making is noteworthy (see Agyeman, 2005; Schroeder et al., 2008). Yet, it can be speculated that one of the reasons that an allocation of oil revenue was rejected is the potential inability to monitor how such money would be utilized for the benefit of affected communities. Some people thought this proposed amount "was going to be used as

10 See https://www.ghanaweb.com/GhanaHomePage/NewsArchive/Western-region-deserves-15-oil-cash-513242 (accessed May 29, 2019). 
royalties for Nananom [i.e. chiefs]" (interview with Paramount Chief of Lower Dixcove \& VP of Western Regional House of Chiefs, Dixcove). This speculation seems warranted because the status of chiefs in local communities gives them direct access to certain benefits that the average community member does not receive.

A fisherman in Axim indicated in an interview that "the compensation that comes is normally pocketed by the authorities." As the custodians of most communities and often the first point of contact, TOCs and powerful organizations sometimes deal with chiefs and elders to the neglect of average community members. To further reiterate the discussion on power differentials, chiefs in this case have high or strong power although this also fluctuates from time to time depending on what issue they are focusing on, and which actors they are engaging with. In a way, this explains why their request for $10 \%$ oil revenue has not materialized into a substantive policy, although they still maintain the authority to receive benefits from corporations and other hydrocarbon actors on behalf of their respective communities. Here, we see how power, scale and injustice intersect in both the explicit and implicit roles of chiefs in a hydrocarbon economy even though the chiefs function at a supposedly 'local' level of governance and administration.

\section{Conclusion}

This article has sought to shed some empirical light on theoretical discussions around the role and essence of power, scale and (in)justice in the manifestation of socio-ecological and political processes. While a great deal has been written about these themes in the extant literature (see Walker, 1998; Watts, 2000; Robbins, 2004; Agyeman, 2005; Walker \& Bulkeley, 2006; Nygren \& Rikoon, 2008; Moore, 2008; Holifield et al., 2009; Walker, 2012; White, 2013; Agyeman \& McEntee, 2014), the article's contribution has been twofold. First, it contextualizes the role of power in extractivism broadly and the political ecology of hydrocarbon extraction in particular by using the case of Ghana to highlight how power circulates, gets distributed and informs people's access to things based on a plethora of factors such as who they are, whom they know and the group(s) they belong to. Closely related to the question of power is the politics that is involved in how decisions are made (and in some cases, not made) around access, participation, distribution of benefits and harms as well as justice. This contribution reveals the potency of power as entailing the ability to enact and control the multiple environments that different actors live and operate in.

The second contribution involves an understanding of the multi-scalar structures that underpin a hydrocarbon economy and its relationship with human-environmental interactions. I have argued in this article that such a multi-dimensional perspective on hydrocarbon extractivism introduces an important element of complexity in how we navigate and explain the actors and structures of power involved in this endeavour as well as potential outcomes. For instance, the discussion of scale specifically points to the relational nature of the different levels (i.e. global, national, sub-national, local) at which the socio-ecological 'goods' and 'bads' of hydrocarbon extraction manifest themselves. As a contribution to recent scholarship on the topic (see, for instance, Obeng-Odoom, 2014; Ayelazuno, 2014; Ablo \& Overå, 2015; Siakwah, 2017, 2018; Ablo, 2018; Andrews \& Siakwah, 2021), this perspective moves us a step further in the typical resource curse theorizing that tends to maintain a technocratic focus on institutions (i.e. the failure thereof of state/domestic institutions) to determine whether extraction will result in material benefits for host communities and countries. The complexity presented in this article shows that there are many considerations at play that mediate and shape both the intended and unintended outcomes of resource extraction.

In conclusion, this article augments debates on political ecology both as a theoretical perspective and as a tool to facilitate a meaningful understanding of social justice and sustainable livelihoods or human wellbeing. In particular, it points to how drawing from assemblage thinking informs the political ecology of hydrocarbon extraction by unveiling the nested set of actor-coalitions and asymmetrical relations of power that condition the distributional politics and injustice associated with resource extraction. 


\section{References}

Abdulai, A. G. (2014). Rethinking spatial inequalities in development: the primacy of politics and power relations. ESID Working Paper No. 29, University of Manchester.

Ablo, A. D. (2018). Scale, local content and the challenges of Ghanaians employment in the oil and gas industry. Geoforum, 96, 181-189. https://doi.org/10.1016/j.geoforum.2018.08.014

Ablo, A. D., \& Overå, R. (2015). Networks, trust and capital mobilisation: Challenges of embedded local entrepreneurial strategies in Ghana's oil and gas industry. The Journal of Modern African Studies, 391413.

Ackah-Baidoo, A. (2013). Fishing in troubled waters: Oil production, seaweed and community-level grievances in the Western Region of Ghana. Community Development Journal, 48(3), 406-420.

Adusah-Karikari, A. (2015). Black gold in Ghana: Changing livelihoods for women in communities affected by oil production. The Extractive Industries and Society, 2(1), 24-32.

Agyeman, J. (2005). Sustainable communities and the challenge of environmental justice. New York University Press.

Agyeman, J., \& McEntee, J. (2014). Moving the field of food justice forward through the lens of urban political ecology. Geography Compass, 8(3), 211-220.

Amongin, S. (2020). Engendering the blue economy: offshore oil extraction and the livelihoods of women in Ghana. MA thesis, University of Northern British Columbia. http://doi.org/10.24124/2020/59026

Andrews, N. (2021). Manifestations of corporate social responsibility as sensemaking and sensegiving in a hydrocarbon industry. Business and Society Review, 1- 24. https://doi.org/10.1111/basr.12236

Andrews, N. (2013). Community expectations from Ghana's new oil find: conceptualizing corporate social responsibility as a grassroots-oriented process. Africa Today, 60(1), 55-75.

Andrews, N., \& Nwapi, C. (2018). Bringing the state back in again? The emerging developmental state in Africa's energy sector. Energy Research \& Social Science, 41, 48-58.

Andrews, N., \& Siakwah, P. (2021). Oil and development in Ghana: beyond the resource curse. Routledge.

Andrews, N., Bennett, N. J., Le Billon, P., Green, S. J., Cisneros-Montemayor, A. M., Amongin, S., ... \& Sumaila, U. R. (2021). Oil, fisheries and coastal communities: A review of impacts on the environment, livelihoods, space and governance. Energy Research \& Social Science, 75, 102009. https://doi.org/10.1016/j.erss.2021.102009

Appel, H.C. (2012). Walls and white elephants: Oil extraction, responsibility, and infrastructural violence in Equatorial Guinea. Ethnography, 13(4), 439-465.

Ayanoore, I. (2018). Oil governance in Ghana: Exploring the politics of elite commitment to local participation. PhD dissertation, University of Manchester.

Ayelazuno, J. (2014). Oil wealth and the well-being of the subaltern classes in Sub-Saharan Africa: A critical analysis of the resource curse in Ghana. Resources Policy, 40, 66-73.

Blaikie, P.M. (2012). Should some political ecology be useful? The inaugural lecture for the Cultural and Political Ecology Specialty Group, Annual Meeting of the Association of American Geographers, April 2010. Geoforum, 43(2), 231-239.

Bryant, R. L. (1998). Power, knowledge and political ecology in the third world: A review. Progress in Physical Geography, 22(1), 79-94.

Bryant, R. L. \& Bailey, S. (1997). Third world political ecology. Routledge.

Cavnar, A. (2008). Averting the resource curse in Ghana: The need for accountability. Ghana Center for Democratic Development (CDD-GHANA).

Charles, A. (2012). People, oceans and scale: Governance, livelihoods and climate change adaptation in marine social-ecological systems. Current Opinion in Environmental Sustainability, 4(3), 351-357.

Creswell, J. W. \& Poth, C. N. (2017). Qualitative inquiry and research design: Choosing among five approaches. Sage. 
Gilberthorpe, E., \& Rajak, D. (2017). The anthropology of extraction: Critical perspectives on the resource curse. The Journal of Development Studies, 53(2), 186-204.

Gioia, D. A., Corley, K. G., \& Hamilton, A. L. (2013). Seeking qualitative rigor in inductive research: Notes on the Gioia methodology. Organizational Research Methods, 16(1), 15-31.

Graham, E., Ackah, I., Andrews, N., \& Van Gyampo, R. E. (2019). Escaping the 'oil curse': Is Ghana on the right path? African Review, 46(1), 235-263.

Gyampo, R. (2010). Saving Ghana from its oil: A critical assessment of preparations so far made. African Research Review, 4(3), 1-16. http://doi.org/10.4314/afrrev.v4i3.60138

Gyimah-Boadi, E., \& Prempeh, H. K. (2012). Oil, politics, and Ghana's democracy. Journal of Democracy, 23(3), 94-108.

Gleeson, B. \& Low, N. (2002). Justice, society and nature: An exploration of political ecology. Routledge.

Haarstad, H. (2014a). Cross-scalar dynamics of the resource curse: Constraints on local participation in the Bolivian gas sector. Journal of Development Studies, 50(7), 977-990.

Haarstad, H. (2014b). Climate change, environmental governance and the scale problem. Geography Compass, 8(2), 87-97.

Hewitson, L. J., \& Sullivan, S. (2021). Producing elephant commodities for 'conservation hunting' in Namibian communal-area conservancies. Journal of Political Ecology, 28(1), 1-24. https://doi.org/10.2458/jpe.2279

Holifield, R., Porter, M., \& Walker, G. (2009). Spaces of environmental justice: Frameworks for critical engagement. Antipode, 41(4), 591-612.

Jessop, B. (2007). State power: A strategic-relational approach. Polity Press.

Lasswell, H. D. (1950). Politics: Who gets what, when, how. P. Smith.

Latour, B. (2005). Reassembling the social: An introduction to actor-network-theory. New York: Oxford University Press.

Le Billon, P. (2001). The political ecology of war: natural resources and armed conflicts. Political Geography, 20(5), 561-584.

Marston, S. A., Jones III, J. P., \& Woodward, K. (2005). Human geography without scale. Transactions of the Institute of British Geographers, 30(4), 416-432.

Mollett, S., \& Faria, C. (2013). Messing with gender in feminist political ecology. Geoforum, 45, 116-125.

Moore, A. (2008). Rethinking scale as a geographical category: from analysis to practice. Progress in Human Geography, 32(2), 203-225. https://doi.org/10.1177/0309132507087647

Neumann, R. P. (2009). Political ecology: Theorizing scale. Progress in Human Geography, 33(3), 398-406.

Nie, Y. (2017). Combining narrative analysis, grounded theory and qualitative data analysis software to develop a case study research. Journal of Management Research, 9(2), 53-70.

Nyantakyi-Frimpong, H., \& Bezner Kerr, R. (2017). Land grabbing, social differentiation, intensified migration and food security in northern Ghana. The Journal of Peasant Studies, 44(2), 421-444.

Obeng-Odoom, F. (2014). Measuring what? "success" and "failure" in Ghana's oil industry. Society \& Natural Resources, 27(6), 656-670.

Oduro, F., Mohammed, A., \& Ashon, M. (2014). A dynamic mapping of the political settlement in Ghana. ESID Working Paper No. 28, University of Manchester.

Okpanachi, E., \& Andrews, N. (2012). Preventing the oil "resource curse" in Ghana: Lessons from Nigeria. World Futures, 68(6), 430-450.

Osei-Kojo, A., \& Andrews, N. (2020). A developmental paradox? The "dark forces" against corporate social responsibility in Ghana's extractive industry. Environment, Development and Sustainability, 22(2), 1051-1071.

Ovadia, J. S. (2016). Local content policies and petro-development in Sub-Saharan Africa: A comparative analysis. Resources Policy, 49, 20-30. 
Paulson, S., Gezon, L. L., \& Watts, M. J. (2003). Locating the political in political ecology: An introduction. Human $\quad$ Organization, $205-217$. https://doi.org/10.17730/humo.62.3.e5xcjnd6y8v09n6b

Phillips, J., Hailwood, E., \& Brooks, A. (2016). Sovereignty, the 'resource curse' and the limits of good governance: A political economy of oil in Ghana. Review of African Political Economy, 43(147), 2642.

Robbins, P. (2004). Political ecology: A critical introduction. Blackwell.

Saldaña, J. (2015). The coding manual for qualitative researchers. Sage.

Saillard, E. K. (2011). Systematic versus interpretive analysis with two CAQDAS packages: NVivo and MAXQDA. Forum Qualitative Sozialforschung/Forum: Qualitative Social Research 12(1).

Schroeder, R., Martin, K. S., Wilson, B., \& Sen, D. (2008). Third world environmental justice. Society \& Natural Resources, 21(7), 547-555. https://doi.org/10.1080/08941920802100721

Siakwah, P. (2017). Actor Network Theory, globalised assemblages and the impact of oil on agriculture and industry in Ghana. The Extractive Industries and Society, 4(3), 462-472.

Siakwah, P. (2018). Actors, networks, and globalised assemblages: Rethinking oil, the environment and conflict in Ghana. Energy Research \& Social Science, 38, 68-76.

Schlosberg, D. (2013). Theorising environmental justice: The expanding sphere of a discourse. Environmental Politics, 22(1), 37-55.

Schlosberg, D. (2007). Defining environmental justice: Theories, movements, and nature. Oxford University Press.

Smith, J.L. (2010). Biofuels and the globalization of risk: The biggest change in North-South relationships since colonialism. Zed.

Svarstad, H., \& Benjaminsen, T. A. (2020). Reading radical environmental justice through a political ecology lens. Geoforum, 108, 1-11. https://doi.org/10.1016/j.geoforum.2019.11.007

Svarstad, H., Benjaminsen, T. A., \& Overå, R. (2018). Power theories in political ecology. Journal of Political Ecology 25, 350-363. https://doi.org/10.2458/v25i1.23044

Swyngedouw, E., \& Heynen, N. C. (2003). Urban political ecology, justice and the politics of scale. Antipode, 35(5), 898-918.

Sze, J., \& London, J. K. (2008). Environmental justice at the crossroads. Sociology Compass, 2(4), $1331-1354$.

Walker, G. P. (2009). Globalizing environmental justice: The geography and politics of frame contextualization and evolution. Global Social Policy, 9(3), 355-382.

Walker, G. P. (2012). Environmental justice: concepts, evidence and politics. Routledge.

Walker, G. P., \& Bulkeley, H. (2006). Geographies of environmental justice. Geoforum, 37(5), 655-659.

Walker, P. (1998). Politics of nature: An overview of political ecology. Capitalism Nature Socialism, 9(1), 131-144. https://doi.org/10.1080/10455759809358786

Watts, M. J. (2004). Antinomies of community: Some thoughts on geography, resources and empire. Transactions of the Institute of British Geographers, 29(2), 195-216. https://doi.org/10.1111/j.0020-2754.2004.00125.x

Watts, M. J. (2000). Political ecology. In Sheppard, E. \& Barnes, T. J. eds., A companion to economic geography, pp. 257-274. Blackwell.

White, R. (2013). Resource extraction leaves something behind: Environmental justice and mining. International Journal for Crime, Justice and Social Democracy, 2(1), 50-64.

Yin, R. K. (2017). Case study research and applications: Design and methods. Sage.

Zalik, A. (2009). Zones of exclusion: Offshore extraction, the contestation of space and physical displacement in the Nigerian Delta and the Mexican Gulf. Antipode, 41(3), 557-582.

Zimmerer, K. S., \& Bassett, T. J. eds. (2003). Political ecology: An integrative approach to geography and environment-development studies. Guilford Press. 